\title{
Approaching lean product development using system dynamics: investigating front-load effects
}

\author{
Alemu Moges Belay • Torgeir Welo • \\ Petri Helo
}

Received: 13 February 2014/Accepted: 29 April 2014/Published online: 27 May 2014

(C) Shanghai University and Springer-Verlag Berlin Heidelberg 2014

\begin{abstract}
Competing with successful products has become perplexing with several uncertainties and transmutes from time to time as customers' expectations are dynamic. That is why manufacturing firms exhaustively strive to look for a better competitive frontier using wellestablished and innovative product development (PD) processes. In this paper, we would like to answer three research questions: (i) What would be the effects of frontloading in PD? (ii) Can we improve our PD process endlessly? (iii) When is the critical time that the firm should take remedial action for improvements? As a contribution to the vast numbers of improvement methods in new product development (NPD), this paper investigates the effects of front-loading using set-based concurrent engineering (SBCE) on cost and lead time. Models are developed and treated using a system dynamics (SD) approach. We assign a hypothetical upfront investment for SBCE and compare its effects on total cost and lead time of the development process. From the research, it is found that the total cost of PD is reduced almost by half — although the front loading is higher in order to encompass multiple design alternatives. The total product lead time is reduced by almost $20 \%$. The model reveals the critical time for improvement of the PD process. We use SD tool (e.g., STELLA) for simulation and visualization of the complex
\end{abstract}

\footnotetext{
A. M. Belay $(\bowtie) \cdot T$. Welo

Department of Engineering Design and Materials, Norwegian University of Science and Technology, Richard Birkelands Vei 2B, N-7491 Trondheim, Norway

e-mail: alemu.m.belay@ntnu.no

A. M. Belay · P. Helo

Department of Production Technology, University of Vaasa, P.O. Box 700, FI-65101 Vaasa, Finland
}

PD model, using SBCE as one of several strategies to frontload activities in the NPD process.

Keywords Front-loading - Set-based concurrent engineering (SBCE) · Innovation · Lean product development (LPD) · System dynamics (SD)

\section{Introduction}

Stiff competition makes new products to be considered as a global confrontation since the last few decades. Hence companies ceaselessly strive to improve and establish new strategies, engineering methods and techniques. The wellknown lean philosophy has been adapted to several applications and obtained both successes and failures, depending on the nature of the new product development (NPD) environment and the requirements of the philosophy by itself. One proven strategy to compete and win in the dynamic and vibrant automotive market is the one due to Toyota which is widely discussed by Morgan and Liker [1] among others. In a more general context, however, competing with new product demands radical changes and significant continuous efforts. This may involve changing strategies (at different levels), product development (PD) processes, culture and mind-set, along with practices such as transforming from sequential to concurrent engineering, adopting components of the lean concept in NPD, e.g., applying set-based concurrent engineering (SBCE) instead of conventional point based concurrent engineering (PBCE).

In this paper, lean is viewed as an umbrella which constitutes several blocks of engineering methods and techniques. These blocks mainly serve to eliminate waste. However, relatively limited qualitative research has been 
carried out on lean that focuses on value adding activities and optimizing NPD processes. Despite the presence of multiple methods and approaches, companies still struggle in their efforts for more profitable and successful new products.

In manufacturing firms that develop and deliver products, cost, time and quality are the three main dimensions of competition. Being one of the main components of the lean philosophy when applied to NPD, concurrent engineering is one of the commonest strategies to improve the performances of these three distinct dimensions. In this context, transforming from a sequential PD to simultaneous engineering is considered as a competitive weapon [2].

In the present paper, attempts will be made to analyze and compare NPD outcomes in terms of two different strategies associated with concurrent engineering, that is, SBCE and PBCE. In NPD, analyzing interdependent activities with several factors is challenging and even more difficult to quantify the effects of various parameters on PD performance. To overcome this challenge, we consider NPD as a system and propose using a system dynamics (SD) approach. The assumption is made because SD is a well-developed theory applicable to consider complex systems, non-linearity, and several feedback loops of information in a system [3].

Before explaining the general structure of the paper, some definitions of the key terms are made as follows:

(i) Front-loading is defined as "a strategy that seeks to improve development performance by shifting the identification and solving of problems to earlier phases of a product development process" [4].

(ii) SBCE has not a single definition and is rather identified by its principles. We combine some views of SBCE in Refs. [5, 6], and rewrite its definition: SBCE is considered as the second Toyota paradox and an approach of reasoning, developing, and communicating ambiguously about sets of solutions in parallel and relatively independently, making late decisions in the best ongoing converging solutions to develop a product faster and cheaper-unlike PBCE which iterates only on a single solution.

(iii) Lean product development (LPD) is an approach attempting to maximize value, increase quality, shorten lead time, and decrease costs in PD processes [7].

The whole process of PD would be considered as system of systems including all efforts to achieve time-to-market and satisfy customers by large. This is because all functions have their own people, processes and technologies which are the basic requirements to be a system. However, the previous trends of PD process show that firms are only focusing on the certain parts of the development processes to enhance their performances, e.g., improvement efforts on design. Obviously, this will improve some parts but not the whole development process and at the end of the day, the product fails. Our motivation is based on Cooper who claims that out of the total four products [8], three fail and an urgent calls by Hoppmann et al. [9], Liker and Morgan [10] to view PD in systems perspective. We understand how complex it would be to develop a model that includes all parts of the development process. Our study is limited only on two functions. This paper looks into the improvement efforts at design stage and sees the overall effects of the CE in terms of cost and lead time. In addition, efforts have been made to analyze marketing as a separate system in PD process and as a part of the whole. This is to show the challenges of controlling and making decisions in a single system letting alone several systems. This encourages and shows the significance of system of system a engineering to have an overall insight on the outputs from the interaction of several systems.

The paper is structured as follows. It starts with a brief introduction and discusses the problem statement of the research followed by explaining the main issues and contexts. It begins by explaining the different views on lean thinking beyond eliminating waste before going into NPD process and decision making. Next, it discusses SBCE and PBCE in terms of speed to market and the role of SD in PD. Before drawing the conclusions, the model with causal loops and the results of SD simulations are presented.

\section{LPD beyond waste elimination}

The industrial revolution in the 1970s brought the emergence of lean thinking in operations management. However, it has been applied in manufacturing and mainly on high volume products. Although lean business management and production strategy is considered as a major and successful Toyota's production system, its principles have been broken down and applied into several detailed operational practices and applications. Nowadays, it is common to see lean as a prefix to different fields and operations: lean six-sigma, lean supply chain, lean construction, lean project management, LPD, etc. Almost all of them focus on eliminating waste that is exactly emanated from the basic single perspective of lean, which is "waste elimination". Pettersen [11] argued that there was no agreement upon definition of lean and the formulations of the overall purpose of the concepts were instead going divergent. Dennis and Bicheno $[12,13]$ linked waste elimination to values that were added for customers. 


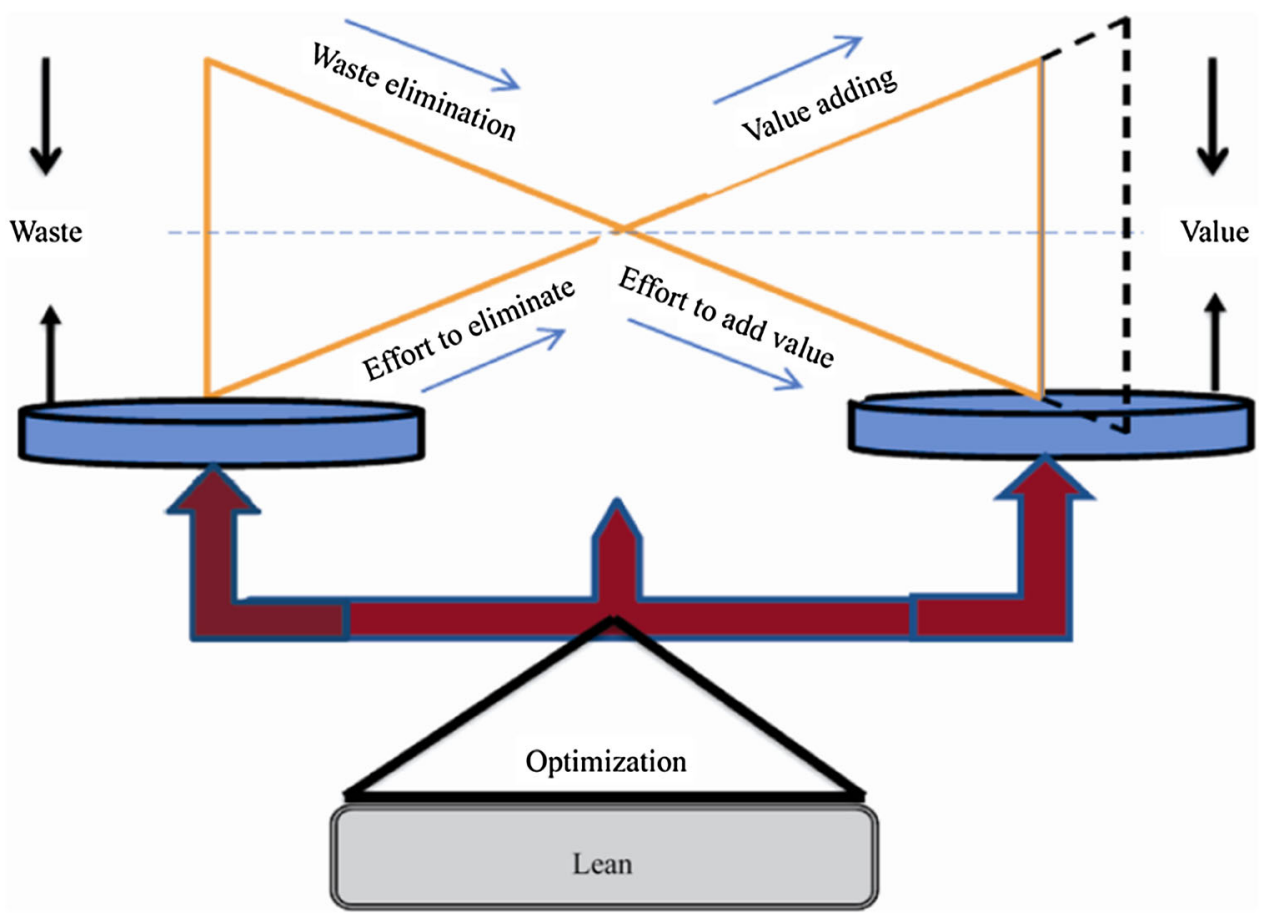

Fig. 1 Lean beyond eliminating waste in NPD

Having reviewed literatures of LPD [14, 15], we develop the conceptual model that broadens the perspective and understanding of LPD beyond eliminating waste. Figure 1 depicts, but several authors also argue, there are at least two factors repeatedly mentioned in the LPD process, namely, waste and value $[1,15]$. In the conceptual model developed, we want to view from other factors too. For example, the left part of the model shows that as we keep eliminating waste, the amount of efforts will reduce and the value added may increase. On the other hand, as firms keep trying to add value the efforts or resource requirements also increase whereas waste may reduce. In general, these efforts are like force field analysis, and the two factors oppose each other and these should be balanced when finding the optimized solutions. However, the objective of the model is to show that values may not be necessary from waste elimination but it can be from other knowledge based activities like product innovation, knowledge and skilled developed through the entire PD process. In the model, the broken line shows the extra value added without significant effort to eliminate waste. Lean as a foundation requires several optimization methods (see Fig. 2) and tools for the betterment of LPD process and subsequent decision making, for example SD.

As a summary, the lean concept applied to NPD should be viewed beyond eliminating waste even more than in the context of production. In this connection, the value should not be limited to the outcome of the considered project but also to more strategic factors such as knowledge creation (explicit and tacit), innovation, creativity, competence and skills builtup, development of people, reuse and standardization.

\section{PD process and design decisions}

NPD process encompasses the sequence of events from idea/concept generation through product delivery to warranty and service related activities. An increasingly popular trend is to consider NPD as a closed loop cycle from a cradle-to-cradle perspective. Our intention here, however, is to limit the focus to the NPD stages before the design freeze and study how investments made on the front-end potentially may affect the outcomes in terms of overall cost and lead time.

The ultimate objective of NPD is to satisfy customers in different dimensions based on their needs. Customers may have explicit or tacit needs, wants, and sometimes they have ideas, sketches, concepts or specific requirements as input to the marketing and NPD groups. All customer problems are converted into the needs and requirements to have a fundament for developing design solution that solves the basic problem. Various methods are used to capture customer needs and cover the spectrum of anthropological approaches to blue print design.

The next stage after need capture is the concept development. To develop a design with optimum performance, it is important to mitigate the risk through reuse of knowledge, test several alternatives (test-then-design) [16, 17], 

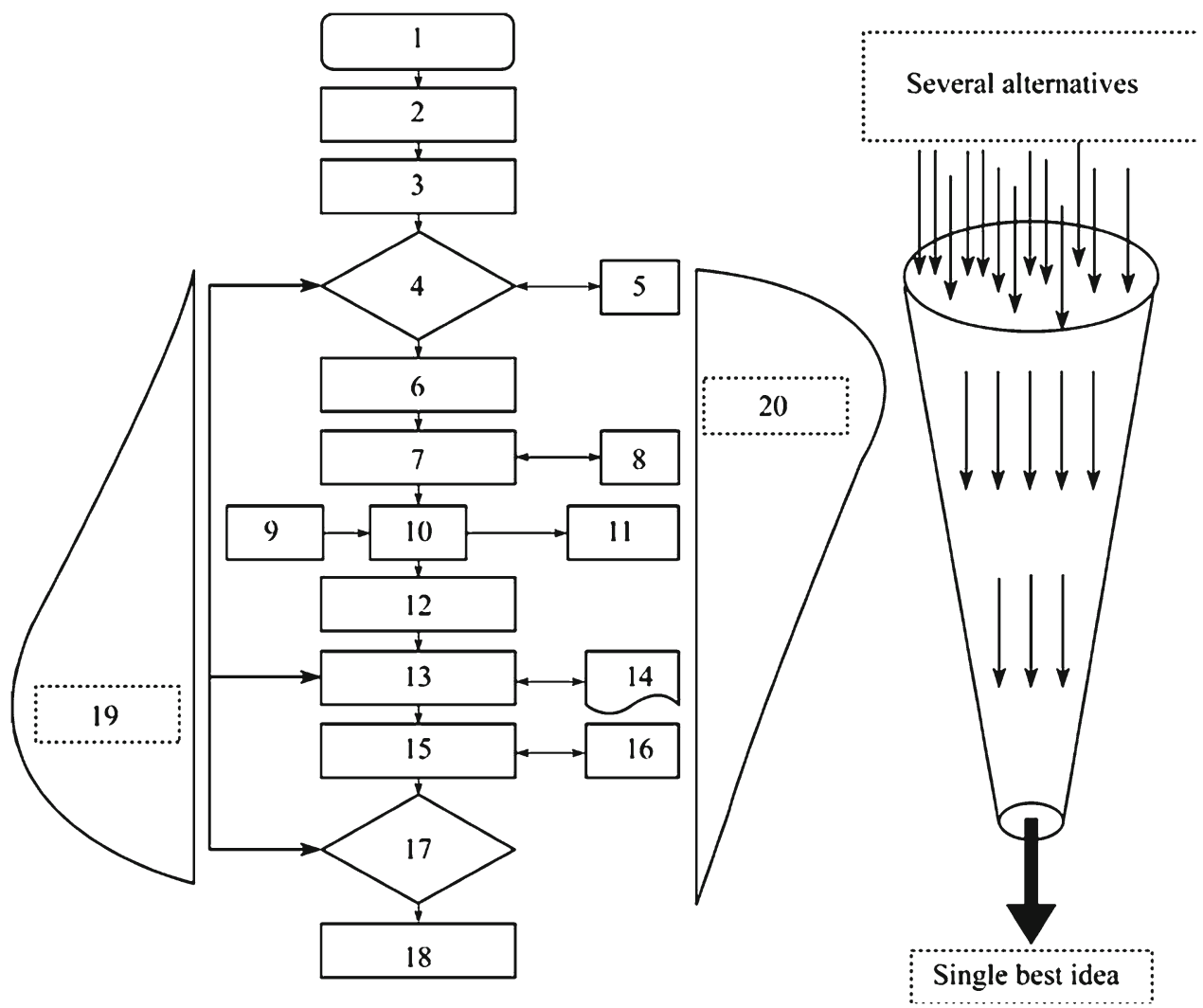

1. In coming customer needs and requirements

2. Marketing meet technical people, agree delivery schedule time 3. Problem (need converted to a problem)
4. Understand the problem
5. Ask customer
9. Concept screening
10. Concept scoring

6. Concept development starting from what you know $\&$ try several approaches 7. Paper design or sketch and compare with other alternatives

8. Evaluate \& modify
11. Concept ranking

12. Synthesis (select the best or combine better concepts)

13. Design, simulation, review, automated drafting, geo. modeling, engineering analysis

14. Documentation

15. Problem (need converted to a problem)
16. Buy parts and spare parts

17. Ask customer for confirmation

18. Production

19. PBCE-late resource allocation 20. SBCE-early resource allocation

Fig. 2 Early stage PD process in PBCE and SBCE with resource distribution (legend 1-20)

start preliminary design and delay design freeze within the critical path of the project to capture as much learning as possible before final design decisions are made. The concept development stage may require preparation of a decision-making matrix for concept screening, scoring and ranking ("Pugh-matrix"). The high ranking concept is carried forward to the next development. Product design documentation has to be developed along other activities to ensure compliance to legalizations, codes, requirements and business goals, avoiding design re-loops. Resources are also required to develop and integrate suppliers in the NPD process. For example, long lead time items like hard tools have to be kicked before the design is frozen. In the next development stage, different-level prototypes are manufactured and tested, and the cost and performance characteristics are compared with initial goals. When goals are satisfied, the NPD process continues to the manufacturing process (launch) and distribution. Otherwise, a redesign loop is conducted.

In summary, due to the interdependency and relations between various tasks in the NPD process, the cost of doing design changes increases along the development timeline. For the same reason, the risk associated with successfully carrying a change through the NPD system increases exponentially with the number of "nodes", as do the resources necessary to support the change activities. 
Design is the crucial element in PD processes and designers are usually challenged to find design solutions that satisfy predefined constraints and meet the performance requirements. Optimization and design are inseparable in successful PD processes as the product is expected to be efficient and economical. Here, it is noted that PD process is not an easy task and sometimes becomes a very complex process that needs comparing several feasible alternative designs. While designers looking for a feasible solution, iterative processes are imminent and solving the problems by optimization is a must. One of the decisive considerations while designing a new product is the knowhow what to change and how to change, this may be sometimes dependent on the designers' experiences and the availability of resources. In developing complex products, decisions in design are not easy and need well defined optimization problem. Then, all variables that satisfy the objective function and all constraints are determined using an appropriate optimization process and tools. For example, in this paper we would like to minimize the total cost and the total time of production by front-loading using SBCE. As the complexity of the product increases, the more challenging to optimize the objective functions and using computer with advanced software is a must. This research uses one of the SD tools (Stella).

\section{SD for decision making}

Earlier, we realize that any proposed solution to the PD problem must be viewed and interpreted in system terms to visualize and look into the emergent properties. This definitely requires full consideration of the system relationships and should be handled with care to obtain better outputs. This is because, as a system, the emergent properties or results are not mainly from individual properties of the elements that comprise the whole system, but from the interactions between those elements and systems. That is why we want to consider PD as a system considered to be dynamic.

Therefore, in a systems approach, methods, tools that enable one to expose and explore dynamic, emergent properties of the system are absolutely necessary. For this reason the use of dynamic simulation and advanced techniques and approaches is very important. We believe that this is critical while making decision in different functions of the PD processes. Although good decision making is possible at different levels and places of PD processes, the overall results may not be as expected, and therefore it is important to develop a model or a system to view the final results of the whole system.

Generally system thinking is a way of solving specific PD problems where these problems are looked as symptoms of an underlying development system. Unless these problems are addressed on time, they can repeat, grow and expand in the entire PD processes and finally cause unexpected consequences. In connection to tackling such complex process, Forrester developed the idea of SD and Sterman developed a theory to approach complex systems, non-linearity, and with several feedback loops of information in a system. One of the tools that helps to understand the trade-offs in the PD stage is dynamic simulation model. Several researchers applied SD in different areas of study. Marujo [18] applied on rework impact evaluation in overlapped PD schedule and its aim was to reduce the lead-time. He provided general model to estimate the extended design time, strictly related to the necessary rework fraction, considering over-lapped activities using SD. SD is particularly effective for modelling and analyzing how the interactions of structures and policies impact performance in PD projects [19]. They argued that SD models could simulate complement system engineering approaches.

\section{SBCE vs. PBCE}

The main distinctions between SBCE and PBCE are on the balance between the numbers of design alternatives considered at an early stage and the amount of design iteration in the later stages. The former requires more resources upfront but is somehow repetitive and simple, involving innovation in the system whiles minimizing risk compared to the latter. In SBCE, several alternatives are considered and combined, and the weak ones are successively eliminated while keeping one safe alternative based on past experience and knowledge. The better alternative, balancing business goals and customer requirements, is carried forward to the next stage. Another important feature of SBCE is its robustness and organizational knowledge generating capability throughout the development processes. Raudberget found that SBCE had the positive effects on NPD process and product performances in terms of increased innovation capability, reduced product cost and improved product performance [20].

Ford and Sobek [21] studied the set-based theory into a continuum of set-based development plans considering the time of convergence. In addition, they showed how PD managers faced difficulties while making key decisions on how to converge from an initial set of conceptual ideas to one final design idea. For example, from the conceptual representation of PBCE and SBCE (see Fig. 3), we want to visualize in an understandable way the differences between them and see the benefits of SBCE through several alternatives.

In general, the main feature of SBCE is its convergences through time and different stages of the development 

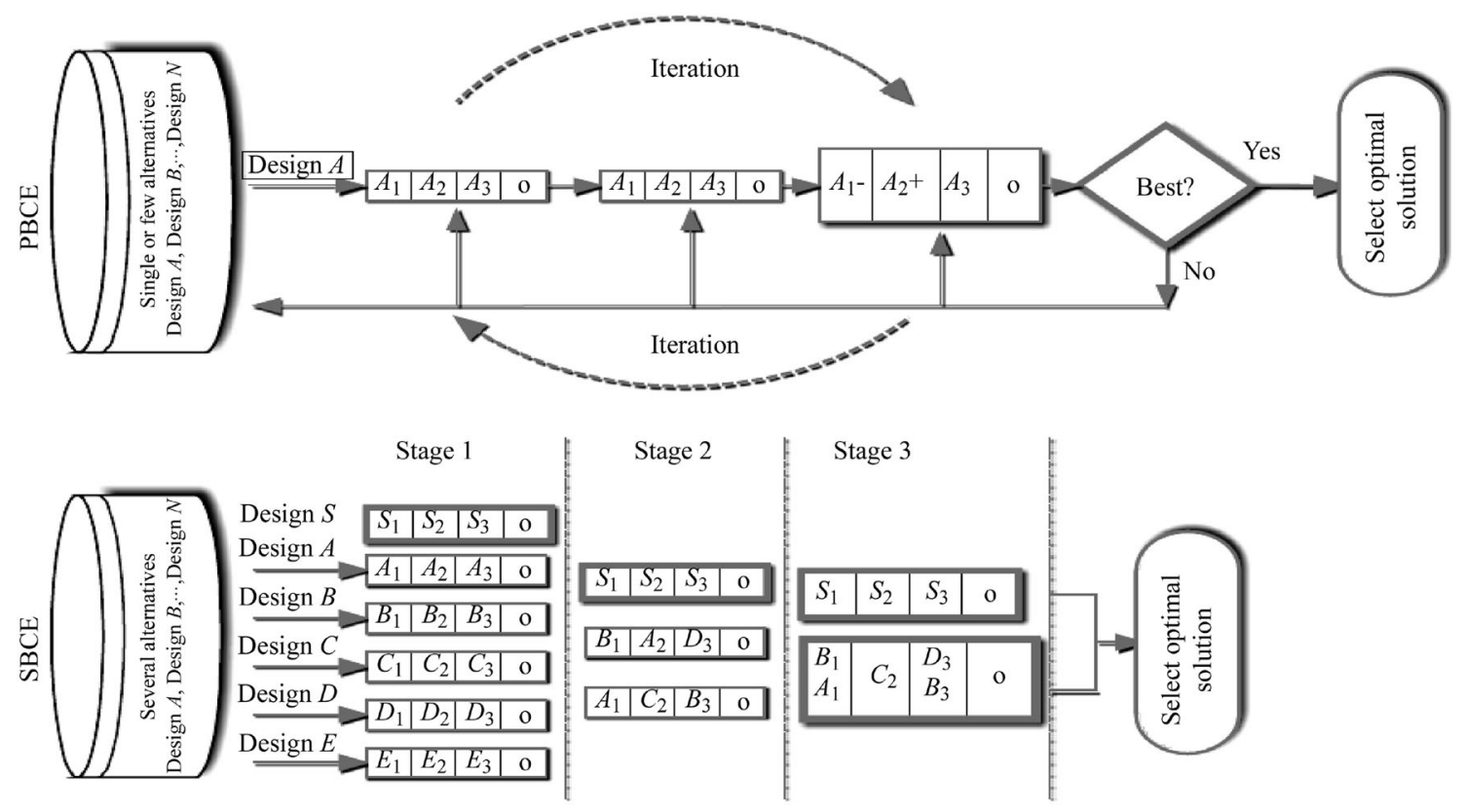

Fig. 3 SBCE vs. PBCE

processes. Belay et al. [22] indicated that convergence of ideas was inevitable for creative NPD. Although the concept of convergence is the pillar in CE in which large scale collaboration thinking leads to understand the ideas for innovation, market, and process and product knowledge, the convergence should not be too fast or slow in one area and should be managed properly, otherwise, the result would be very limited and difficult to obtain well engineered products. Products as well as processes are changing rapidly from one stage to another during the PD process, and learning is factored until a distinct set of processes and products that can emerge into a highly competitive result.

In PBCE, there are very few alternatives at the beginning and perhaps only a single option considered in the product design process. When product teams face challenges or difficulties, modifications and redesign are required. In the iteration process extra resources in terms of people, time and cost are required. Too much iteration may not be economical (further down the time line), more costly and more difficult to move into a conceptually different alternative, forcing the NPD team into a reactive "fix" mode with the minimum organizational knowledge capture. If design iterations are done at an early stage with more buffers to the critical path of the project, however, iterations are a mean to innovate since it brings up multiple alternatives in a broader design space. Hence, the better concepts in the set of alternatives have a better chance of providing the features that would ultimately satisfy customers' needs and requirements.
The conceptual model (see Fig. 3) developed in this paper particularly on SBCE, gives a vacant space for innovative ideas, creativity and development of better options within each stage and alternatives. For example, Design $S$ is the existing development process and it has a space "o" in its activities in all stages. Similarly, other alternatives from $A$ to $E$ have their own spaces. As the PD processes go forward towards different stages, the concept becomes better and better as we avoid the weak ones. However, there is always existing development process as a safety and also the firm should not stop producing products.

\section{Time-to-market, its risks, and roles of SD}

Speed-to-market provides large benefits and is one of the differentiators for product manufacturing firms. The desired outcomes of development time saved are surging profits and dominating market shares, preventing competitors from succeeding. In addition, resources will be freed up for development of new products and/or on strategic research as fundament for innovations and value adding activities. There are several driving forces to reduce cycle time and enter the market faster with new products, including changes in technology, markets and competition. In such a complex and dynamic environment, it is mandatory to improve critical activities in the NPD process. Several studies have shown that increased speed to market requires continuous efforts on improving the early stages in 
NPD [4]. However, it is important to consider the opportunity cost and the risk level before going to decide speeding up the cycle time. In some cases, e.g., when increased speed lacks root in true NPD process improvements, cutting corners may lead to quality sacrifices which in turn may result in customer complaints and lost market shares.

Although firms exhaustively try to speed up their PD processes, especial attention should be given to the risks that are going to be encountered during this effort. In some cases, the cutting corners may lead to quality sacrifices and that in turn result in so many complaints from customers and distributors. If once the customers drift to the competitors, it may be difficult to bring back and the payback period and cost would be very high. Since the ultimate objective of the PD is not only to win speed to market, due attention should be given to the consequences and how the firms should approach the development processes so launch their products faster. Otherwise, only focusing extraordinary efforts in speeding up the development cycle may be mishandled and finally the firm loses the opportunity of having new and novel products to the market. In addition to that, regardless of the firms' endeavour from time to market, the possibilities of producing technologically inferior products and missing some customer requirements are most likely to happen. To overcome such risks, it is important to make products more flexible and analyze systematically to balance both extremes, find optimized and successful products. We want to relate the risk in the context of minimizing the iteration and avoid early freezing of product concept by involving several alternatives as much as possible. However, this requires careful analysis and system thinking to take advantage by using set based strategy.

SD is a methodology for studying and managing complex systems [21]. Since the strategic business goal is to improve from project to project, optimizing the entire process rather than individual steps, we found SD with its causal loop suitable for the present purpose of such complex processes. Using SD to analyze a complex project, Ford and Sterman [23] concluded that a complete causal dynamic model was required to integrate the influences of processes, resources, scope and targets. Another application of SD in a complex PD system has been presented by Lai [24], who considered $\mathrm{SD}$ in combination with support vector machine and rough set method, analyzing feedback loop to determine the nonlinear SD. Ford [25] showed that SD identified structural feedbacks at the operational level that helped to obtain the desired patterns of the specific behavior over time.

\section{Model formulation and effects of front-loading}

Our assumptions are emanated from Prasad [26] who considered revenue following the S-curve and from the relationships of a triangle area, total revenue loss revenue loss $\left(R_{\text {Loss }}\right)$ due to delay in introducing the new product is calculated as

$R_{\text {Loss }}=\frac{R_{\text {Early }}-R_{\text {Delayed }}}{R_{\text {Early }}}$,

where $R_{\text {Early }}$ and $R_{\text {Delayed }}$ are revenue losses due to early and delayed development and time to enter to the market

Table 1 Sensitivity and innovation possibilities due to front-loading

\begin{tabular}{|c|c|c|c|c|c|}
\hline Sim. No. & $\begin{array}{l}\text { Cost before } \\
\text { design } /\left(\times 10^{3} \$\right)\end{array}$ & $\begin{array}{l}\text { Cost after } \\
\text { design/ }\left(\times 10^{3} \$\right)\end{array}$ & $\begin{array}{l}\text { Total time/ } \\
\text { months }\end{array}$ & $\begin{array}{l}\text { Probability of having } \\
\text { innovative product } \\
\left(\left(C_{\mathrm{bd}}-C_{\mathrm{ad}}\right) / C_{\mathrm{bd}}\right)\end{array}$ & $\begin{array}{l}\text { Number of alternatives } \\
\text { due to front-loading }\end{array}$ \\
\hline 1 & 0.1 & 139.9 & 7748 & -138 & Outsource design \\
\hline 2 & 10 & 130 & 1196 & -3 & 1 \\
\hline 3 & 20 & 120 & 832 & 14 & 1 \\
\hline 4 & 30 & 110 & 711 & 26 & 1 \\
\hline 5 & 40 & 100 & 650 & 38 & 1 \\
\hline 6 & 50 & 90 & 614 & 48 & 1 \\
\hline 7 & 60 & 80 & 589 & 59 & 1 \\
\hline 8 & 70 & 70 & 572 & 69 & 1 \\
\hline 9 & 80 & 60 & 559 & 80 & 1 \\
\hline 10 & 90 & 50 & 549 & 89 & 1 \\
\hline 11 & 100 & 40 & 541 & 100 & 5 \\
\hline 12 & 110 & 30 & 534 & 110 & 5 \\
\hline 13 & 120 & 20 & 528 & 120 & 5 \\
\hline 14 & 130 & 10 & 524 & 130 & 5 \\
\hline 15 & 139.9 & 0.1 & 520 & 140 & Outsource production \\
\hline
\end{tabular}


respectively. By following the analogy of Prasad, delay loss can be calculated from a speed up time due to SBCE. Hence, if there are no speed up activities (without SBCE), the PD time will be no speed up factor.

$D_{\text {Loss }}=\frac{S_{\mathrm{s}}-S}{S_{\mathrm{s}}}$,

where $D_{\text {Loss }}$ is delay loss, and $S_{\mathrm{s}}$ the time of development from SBCE and $S$ without SBCE. In our case, we found 540 and 650 months for PD time with and without SBCE, respectively. That is about $20 \%$ improvement at PD time.

$T_{\mathrm{C}}=C_{1}+C_{2}+C_{3}+C_{4}+\cdots+C_{N}$,

where $T_{\mathrm{C}}$ is the total cost and $C_{1}$ individual cost from concept to production. Here we split these costs into two (i.e., $C_{\mathrm{D}}$ cost before design with $\mathrm{SBCE}$ and $C_{\mathrm{T}}$ cost after design)

$T_{\mathrm{C}}=C_{\mathrm{D}}+C_{\mathrm{T}}$.

As an initial assumption, we consider that cost will grow through time and use growth function with $\alpha$ as constant. Integrating the above relationship, this leads to growth function, hence, the initial cost $C_{0}$, comprises two components, i.e., $C_{\mathrm{D}}$ and $C_{\mathrm{T}}$, which from Toyota production system and transformation, i.e., about $80 \%$ of total cost committed at early stages or before design [16, 27-29] is $C_{\mathrm{D}}=0.8 T_{\mathrm{C}}$ and $C_{\mathrm{T}}=0.2 T_{\mathrm{C}}$.

Defining some fraction of cost percentage " $f$ " will change the cost spent before and after design. This could be due to shift from PBCE to SBCE. Therefore,

$C(T)=C_{0} \mathrm{e}^{\alpha T}=0.8 T_{\mathrm{C}} \mathrm{e}^{\alpha T}+0.2 T_{\mathrm{C}} \mathrm{e}^{\alpha T}$.

By balancing the fraction cost percentage $f$ with maximum value of $80 \%$,

$C(T)=C_{0} \mathrm{e}^{\alpha T}=(0.8-f) C_{\mathrm{D}} \mathrm{e}^{\alpha T}+(0.2+f) C_{\mathrm{T}} \mathrm{e}^{\alpha T}$.

Considering $T_{\mathrm{R}}=T_{1}+T_{2}+\cdots+T_{N}$, i.e., $T_{\mathrm{R}}$ is the total rework time and/or iterations in the process and $T_{\mathrm{T}}=T_{\mathrm{P}}+T_{\mathrm{R}}$, in which $T_{\mathrm{P}}$ is the total processing time, i.e., processing and rework time.

By considering some values of initial costs before and after design, for example, 100,000 \$ and 40,000 \$, respectively, we test the impact of SBCE. We run the model by front-loading large resource before design and vice versa. It is found that SBCE improves the total cost almost by half and development time by $20 \%$.

In Table 1 , the sensitivity and probability of carrying out an innovation with several alternative designs that come from the front-loading is summarized based on the assumption made. In general, as we frontload more resource in the early stage, the lead time is reduced and the probability of having innovative product is high. Similarly, the total cost is also reduced as we frontload the resources.

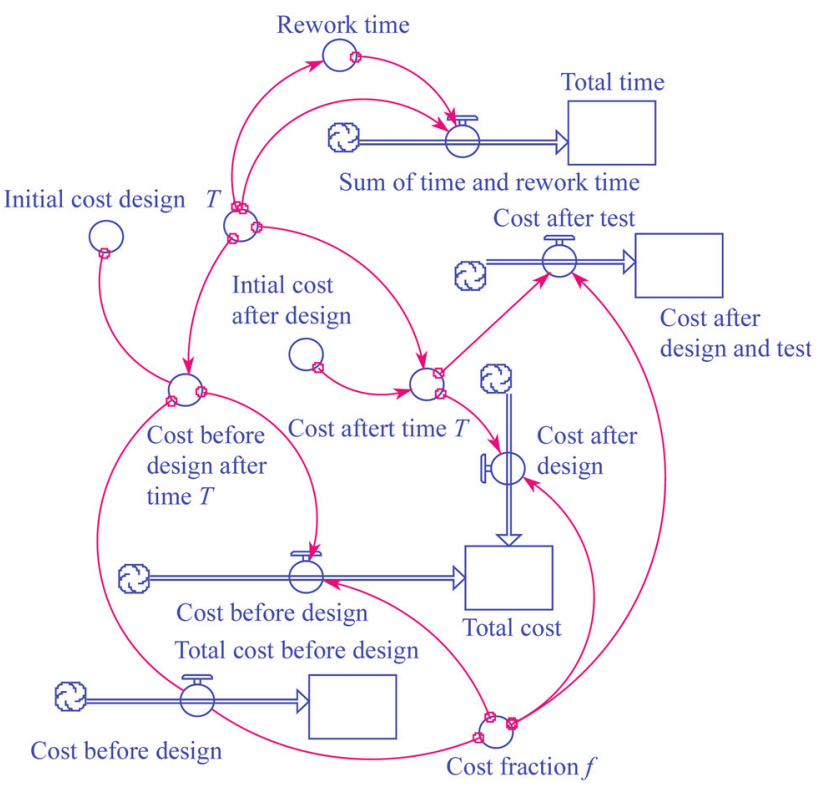

Fig. 4 The model with interactions and relationship to cost and time

For example, in our SBCE vs. PBCE model, we have 5 alternatives that need resources and we assume that an innovation will be carried out at least in one of these alternatives. As shown in Table 1, beginning from simulation No. 11, there is high probability to carry out an innovation from 5 alternatives. In simulation Nos. 1 and 14 there could be a possibility to outsource the design or the production processes. This is for example in a situation when the resource or budget is utilized fully before the design stage or after the design stage.

\section{A model in relationship with frontload and marketing for managing dynamic PD process}

In addition to the general model (see Fig. 4), two other models are developed that would help to manage the dynamic PD processes using SD. In the second model (see Fig. 6), we represent the effect of front-loading with the help of some variables, such as percentage of parallel activities, a number of design teams, etc. Initially, we have some amounts of budgets to run the PD process and a certain amount of expenses to cover the cost during the normal PBCE. However, due to the demand pressure or capacity expansion, the manufacturing firm is forced to improve its speed by the two methods, i.e., by increasing the percentage of parallel activities and/or by increasing the number of design teams. Here, there are two contradicting forces. The first one is the demand pressure that pushes the firm foreword to produce number of products and at faster rate. The other one is the dragging force that hinders the 


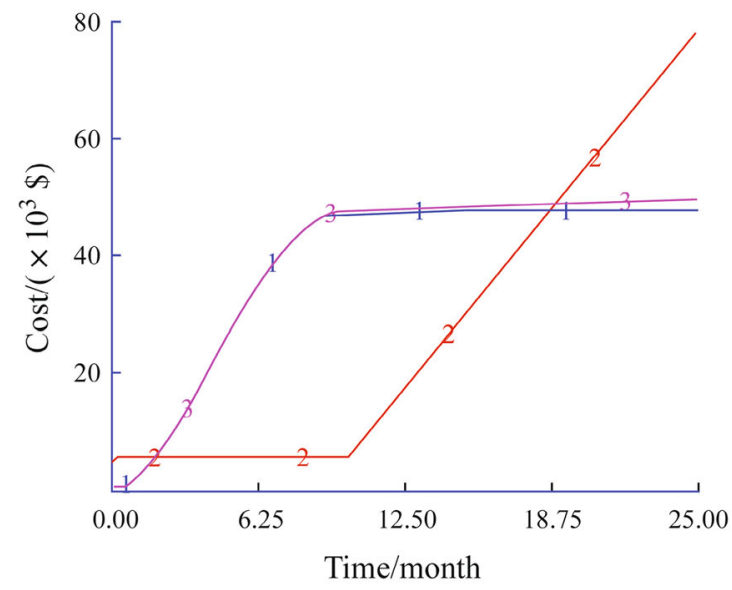

(a) With front-loading

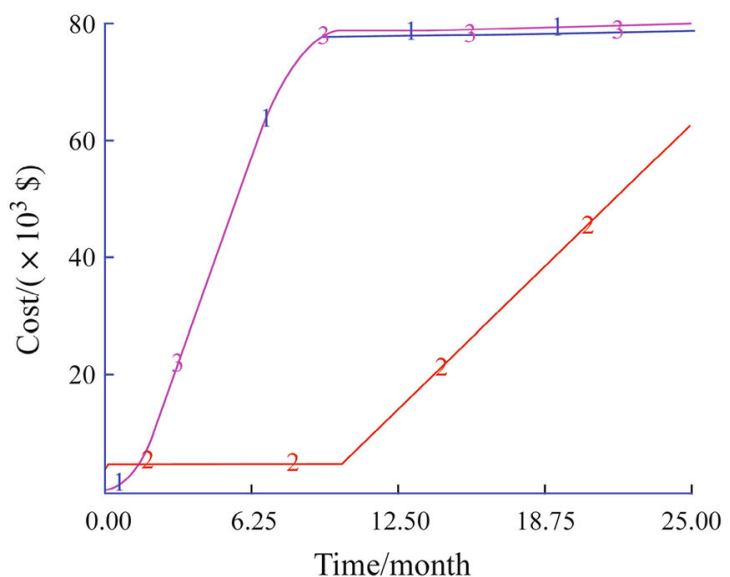

(b) Without front-loading

Fig. 5 Total cost of PD with and without front-loading, where 1 cost after design and test, 2 total cost before design, 3 total cost

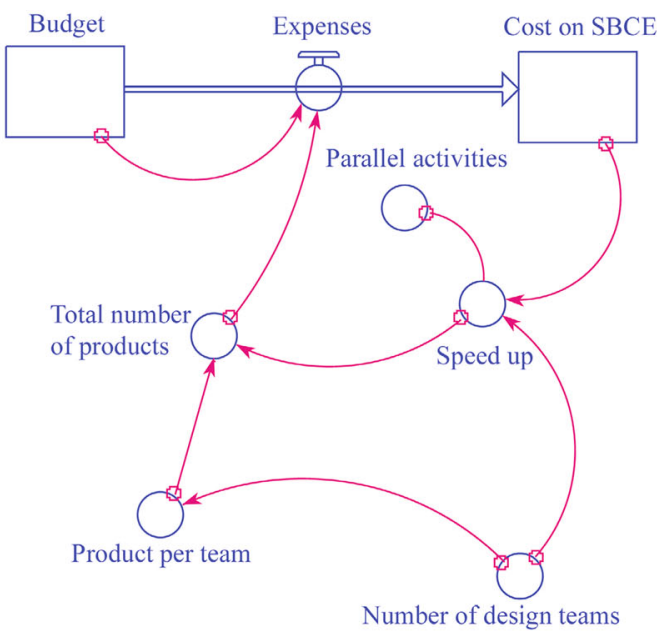

(a)

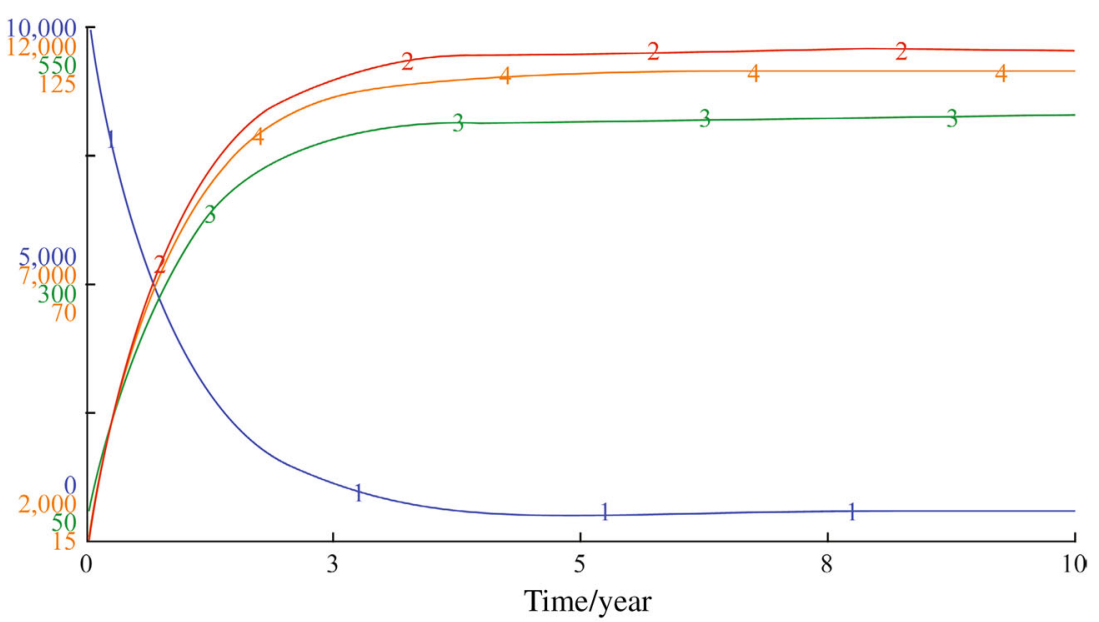

(b)

Fig. 6 SD model to manage a SBCE in cost vs. time, where all costs, e.g., cost on SBCE and budget (1\&2), are in US dollars, total number of products in units (3) and speed up (4) in percentage (\%) 


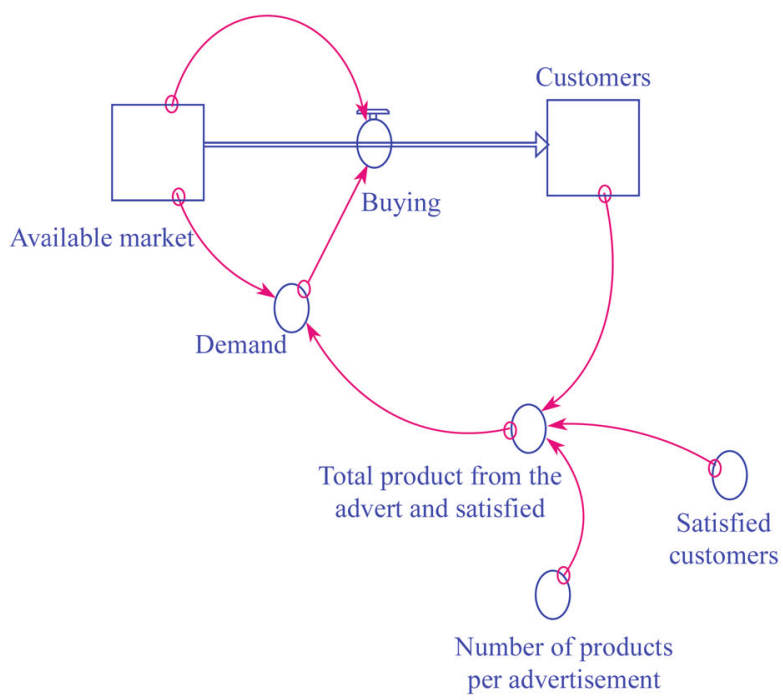

(a)

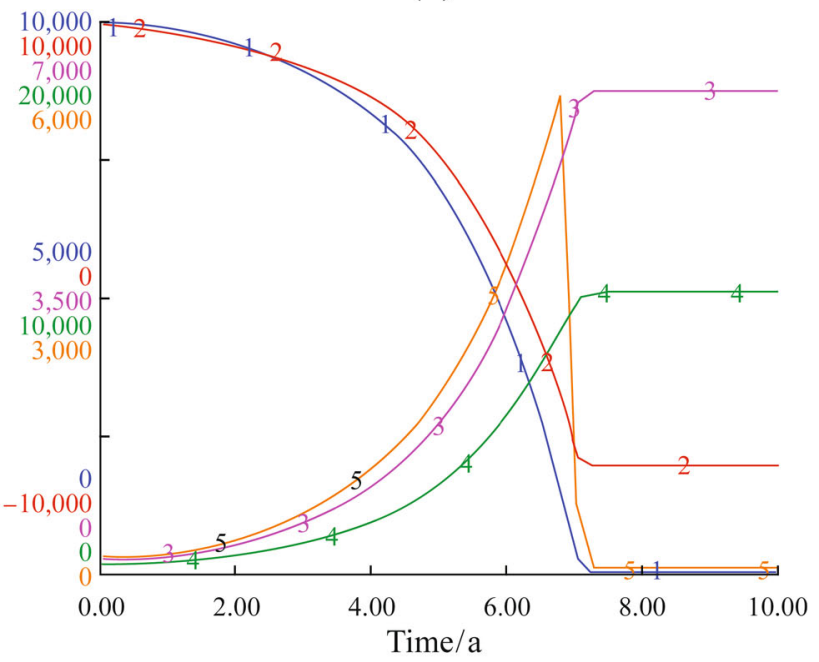

(b)

Fig. 7 (a) A model from marketing to enhance PD performances in cost vs. time, (b) where available potential market (1), demand (2), total products from advert and satisfied customers (3), existing customers (4) and number of buyers or buying (5) are measured in numbers or units

development process due to budget limitations. In short, we cannot improve or speed up and use resources (e.g., the budget) endlessly as these oppose each other. In the model, we assume that the numbers of design teams are proportional to the cost in PBCE and it drives the speed up together with the percentage of parallel activities. The speed up is computed based on Amdahl parallel computing principle. This model would help in response to Sect. 3 and as a part of knowledge based decision support system in SBCE efforts to see when the possible critical time for in PD process. As we see from the simulation results only from concurrent engineering efforts (without marketing), the managers could think of change in the initial years (starting from equilibrium point which is starting from early the beginning years).

The second model (see Fig. 7) is from the marketing perspective that helps to know and determine when the expected demand and number of potential buyers will decline. Having had such information, managers can make strategic knowledge based decisions or look for innovative PD methods and/or value adding activities in advance. The model is based on the marketing theory, i.e., the product will have the growth, the maturity and the decline stage. What makes the SD model significant is that, managers can visualize the interaction between different factors and make it easy to control several nonlinear parameters from the causal loop relationships. Due to space limitation, we are restricted to explain all parameters and details. However, the combined effects from concurrent engineering effort and marketing show the optimum solution that would lead to possible realistic solution for decision making.

\section{Findings and conclusions}

We use a hypothetical value (cost) to test the models developed. First, we assume few resources assigned in the early stage and more resources assigned after the design stage. Then we interchange the case and compare the results. Based on the model in Fig. 4, the results are shown in Fig. 5.

(i) Within the scope of the assumptions made, frontload (e.g., using SBCE) in NPD reduces the total cost by more than half and improves lead time by $20 \%$, resulting in a proportional delay loss when loading resources in the later stage. That may result in lost opportunities in the market place. From the result, the general trends of the cost curves are somehow similar to that of Refs. [27, 28].

(ii) We analyzed the second model (see Fig. 6) by varying different parameters for example, increasing the number of teams in order to see the overall impact. It is found that, we cannot improve continuously the whole PD processes using a few parameters since we have the resource limitations, i.e., budget. However, the model can give an insight to see the optimal solution.

(iii) From the last model in relation to marketing (see Fig. 7), we consider a 10 year PD situation and the result shows beginning of the 7th year the managers should look for sound improvement methods because of the decline in buying and the 
potential market is almost exploited. As a solution, the managers could go for innovative PD processes, apply SBCE, etc.

From the results we can conclude that, if SBCE is analyzed systematically using SD, it will reward significant benefits in terms of reduced cost and lead time. Analyzing the effect of SBCE on product quality beyond the scope of the present work, we believe that exploring the design space with multiple alternatives will have a positive impact on product quality as well if we measure quality in terms of rework rate. Front-loading is one of the core components in LPD and if successfully implemented, firms could be benefited from this strategy. This paper provides three models and analyzes a SD approach that shows the interrelationships between different parameters. We believe a conceptual model developed for SBCE and PBCE will help to understand the differences between the two approaches. As a limitation, the model should be tested in practice and it may give better results by considering more parameters and dimensions, e.g., quality. The future work will combine all these models that are treated separately and develop a holistic model that gives an outlook for sagacious decision making.

\section{References}

1. Morgan JM, Liker JK (2006) The Toyota product development system: integrating people, process and technology. Productivity Press, New York

2. von Wurtemberg LM, Lillieskold J, Ericsson E (2011) Abstract model of LPD: a critical review of the lean product development concept. In: Proceedings of technology management in the energy-smart world (PICMET). July 31-August 4, Portland

3. Sterman J (2000, 2002) Business dynamics: systems thinking for a complex world. World's most powerful production system. Irwin/McGraw-Hill, Productivity Press, New York

4. Thomke, Fujimoto (2000) The effect of front-loading problemsolving on product development performance. J Prod Innov Manag 17(2):128-142

5. Sobek W, Ward AC, Liker JK (1999) Toyota's principles of setbased concurrent engineering. Sloan Manag Rev 40(2):67-83

6. Ward A, Liker J, Cristiano J et al (1995) The second Toyota paradox: how delaying decisions can make better cars faster. Sloan Manag Rev 36(3):43-61

7. León H, Mart C, Farris JA (2011) Lean product development research current state and future directions. Eng Manag J 23(1):29-51

8. Cooper RG (2001) Winning at new products, accelerating the process from idea to launch. Perseus, Cambridge

9. Hoppmann J, Rebentisch E, Dombrowski U et al (2011) A framework for organization lean product development. Eng Manag J 23(1):3-15
10. Liker JK, Morgan J (2011) Lean product development as a systems: a case study of body stamping development at Ford. Eng Manag J 23(1):16-28

11. Pettersen J (2009) Defining lean production: some conceptual and practical issues. TQM J 21:127-142

12. Dennis P (2002) Lean production simplified: a plain language guide to the world's most powerful production system. Productivity Press, New York

13. Bicheno J (2004) The new lean toolbox: towards fast, flexible flow, 3rd edn. PICSIE Books, Buckingham

14. Karlsson C, Ahlström P (1996) The difficult path to lean product development. J Prod Innov Manag 13:283-295

15. Welo $\mathrm{T}$ (2011) On the application of lean principles in product development: a commentary on models and practices. Int J Prod Dev 13(4):316-343

16. Kennedy D (2010) Engineering design and development. First international conference in mechanical technology and structural materials (MTSM). Split, 21-22 Oct 2010

17. Kennedy MN, Harmon K (2008) Ready, set, dominate: implement Toyota's set-based learning for developing products and nobody can catch you! Oaklea Press, Richmond

18. Marujo LG (2009) Rework impacts evaluation through system dynamics approach in overlapped product development schedule. J Technol Manag Innov 4(2):90-101

19. Ford DN, Sterman JD (2003) Overcoming the $90 \%$ syndrome: iteration management in concurrent development projects. Concurr Eng 11(3): 177-186

20. Raudberget D (2010) Practical applications of set-based concurrent engineering in industry. Strojniškivestnik $\mathrm{J}$ Mech Eng 56(11):685-695

21. Ford DN, Sobek DK II (2005) Adapting real options to new product development by modelling the second Toyota paradox. IEEE Trans Eng Manag 52(2):175-185

22. Belay AM, Kekale T, Helo P (2011) Time to market and concurrent engineering in product development processes. Int J Innov Learn 10: 68-84

23. Ford DN, Sterman JD (1998) Dynamic modeling of product development processes. Syst Dyn Rev 14(1):31-68

24. Lai C (2008) Research on modeling of product development complex system based on system dynamics. In: IEEE international symposium on knowledge acquisition and modeling (KAM 08), pp. $361-365$

25. Ford DN (1999) A behavioral approach to feedback loop dominance analysis. Syst Dyn Rev 15:3-36

26. Prasad B (1997) Analysis of pricing strategies for new product introduction. J Prod Brand Manag 5(4):132-141

27. Pesonen (2001) Implementation of design to profit in a complex and dynamic business context. http://herkules.oulu.fi/ isbn9514264509/isbn9514264509.pdf. Accessed 30 Apr 2012

28. Anderson DM (2008) How to design for low cost, design in high quality, design for lean manufacture, and design quickly for fast production. Design for manufacturability and concurrent engineering. CIM Press, Cambria

29. Al-Ashaab (2010) The conceptual lean PPD model. In: The 17th ISPE international conference on concurrent engineering (CE), 6-10 Sept 2010. Cracow, Poland 